\title{
Mujeres, imaginario corporal y prácticas sexuales. Vivencias de la corporalidad y el erotismo ${ }^{1}$
}

Catalina Balbontín Z.²

¿Cómo pensar el lazo que existe entre erotismo e imaginario corporal? Respecto a ello, es quizás interesante atisbar algunas variaciones que se pueden producir en los modos de significar la realidad, cuando las prácticas eróticas varían. Y más aún ¿qué variaciones se pueden producir cuando las prácticas juegan con los límites y en los límites impuestos por la ley de la heteronormatividad?

Es necesario tener presente que la constitución subjetiva se produce en y por las posibilidades de significación y validación de la cultura hegemónica, heteronormativa y de dominación masculina. La formación de un sujeto reconocido por este sistema es un largo proceso de modelar y cincelar bajo las prescripciones dominantes y con las herramientas permitidas. La constitución de un sujeto, la conformación de una identidad van indisolublemente ligadas a un cuerpo, que es significado previamente por la cultura en que se nace. Este yo cuerpo, esta corporalidad subjetivada queda inscrita en una cultura hegemónica heteronormativa, donde el cuerpo en el que se nace marca las vías del deseo y determina la identidad. De este modo es preciso no dejar de considerar que la constitución subjetiva, la identidad, la vivencia de la sexualidad y de la corporalidad son procesos que nunca pueden ser entendidos uno sin el otro.

Considerando que la conformación corporal tanto como la subjetiva son parte de un mismo proceso, delimitado y producido por las técnicas de un poder siempre presente, surge el interés por indagar respecto a la vivencia de un erotismo no normalizado y su relación con el imaginario corporal en mujeres con prácticas que se escapan de la heteronormatividad; qué sucede con 
las significaciones y resignificaciones que estas mujeres realizan respecto a dichas prácticas sexuales y también a los modos de percibir una corporalidad respecto al erotismo. Es decir, aparece el interés por saber si prácticas que desnormalizan la vivencia del deseo, tienen alguna repercusión en las representaciones de un cuerpo que se modeló dentro de una hegemonía significantede dominación masculina y heteronormada.

A partir de tal realidad, surge la pregunta respecto a cómo se construyen, destruyen, deconstruyen y reconstruyen las vías por las que circula un deseo y su imaginario corporal, cuando no hay significantes que faciliten y entreguen previamente algún horizonte que perseguir y cuando los significantes existentes desvalorizan las nuevas posibilidades abiertas. Y si ya las vías presentan grandes diferencias en sujetos cuya experiencia queda bajo la lupa de la heteronormatividad, es también interesante pensar qué caminos, qué vivencias del erotismo y qué relaciones con la corporalidad, existen para los sujetos cuyas prácticas se salen de esa normatividad, ingresando a una dimensión no sólo devaluada, sino también, menos nombrada.

\section{Cuerpo, erotismo, identidad}

Las polaridades -siempre opuestas y complementarias-dan sentido y delimitan nuestra realidad. Oposiciones marcadas por la diferencia, que a su vez, marca jerarquía. Oposiciones que además marcan identidad, que nombran y sitúan algo estático. Lo dual, en este sentido, no permite movimiento, tránsito, cambio, mutación. Lo dual obliga.

La noción de movimiento cuestiona la inmutabilidad de cualquier oposición binaria, diluye tal solidez, sus fronteras, relativiza los márgenes. $\mathrm{Al}$ respecto, Deleuze y Guattari, proponen la figura del rizoma, concepto que proviene de la botánica y se caracteriza por ser un conjunto de tallos subterráneos que generan múltiples ramificaciones en cualquier dirección, desapareciendo cualquier posibilidad de núcleo de origen. En oposición, proponen la noción de árbol, donde las ramificaciones se generan 
a través de formaciones duales y en dirección vertical, remitiéndose siempre a un centro, a un único origen. Con la noción de rizoma, la jerarquía es desplazada. Es así que la corporalidad y la sexualidad no son las mismas entendidas desde lo rizomático o desde lo arborescente. El rizoma "[...] es una liberación de la sexualidad, no sólo con relación a la reproducción, sino también con relación a la genitalidad. Entre nosotros el árbol se ha plantado en los cuerpos, ha endurecido y estratificado hasta los sexos. Hemos perdido el rizoma o la hierba" (Deleuze y Guattari, 2003, 43). El cuerpo se ha endurecido, secado, perdido los fluidos, estancado en una estructura que no permite ningún tránsito para reconocerse como tal.

En relación a lo anterior y como propone Butler (2002), el cuerpo puede ser concebido como una construcción que existe en y a través de las marcas de género, donde el esquema corporal se genera como un proceso de reiteración regulada, bajo el mandato de una serie de prohibiciones fundadoras. Esta repetición continua y obligada, instituye a la sexualidad como un sitio en el que constantemente se reconstituyen los cuerpos.

Así también, Foucault (2002) plantea que el poder actúa de un modo encubierto, pues sólo puede ser entendido a partir de una de sus dimensiones: la represiva. Su dimensión productiva es borrada y nunca vista. De este modo, realizar actos que transgredan los mandatos impuestos a través de los mecanismos del poder, no sólo significa romper determinadas cadenas de represión, sino que también resquebrajar las bases mismas de una constitución subjetiva que fue realizada gracias a estos mecanismos -mecanismos de represión, mecanismos de producción-. De esta manera, en la investigación surgió -en varias de las mujeres- una angustia respecto de las transformaciones que vivían en torno a sí mismas. Quizás agrietar los propios cimientos, a partir de actos que parecieran sólo quebrar murallas ajenas a la propia subjetividad, abre puertas a una intensidad real difícil de significar: lo abyecto. Como señala Kristeva "Hay en la abyección una de esas violentas y oscuras rebeliones del ser contra aquello que lo amenaza y que le parece venir de un afuera o de un adentro exorbitante, arrojado al lado de lo posible y de lo tolerable, de lo pensable. Allí está, muy cerca, pero inasimilable" (Kristeva, 1988, 
7). Lo abyecto perturba un orden, un sistema, una identidad, es una amenaza real, no posible de ser significada. No aparece, irrumpe, de ahí la fuerza de las barreras mantenidas para poder mantenerlo en su lugar.

Por otra parte, realizar prácticas que vayan más allá de la normalización en una matriz de heteronormatividad no garantiza que los modos de significación que de ellas se hagan o se deriven estén teñidos de nuevos modos explicativos de la realidad; no necesariamente implican el cuestionamiento de la hegemonía significante. Esto, precisamente, porque el sistema hegemónico no sólo obliga prácticas y conductas, sino que además brinda las posibilidades discursivas con las que se comprende el mismo y desde las que se genera el mundo en que se vive. De este modo, lograr significar más allá de la heteronormatividad implica complejos procesos de reflexión en torno a las nuevas prácticas que se realizan. Es así, que sólo algunas de las entrevistadas manifestaron nuevos modos de explicación de los sucesos vividos, asumiendo que muchas veces se quedaron sin palabras para poder explicar o incluso para poder entender ellas mismas lo que les estaba sucediendo. Esta falta de significantes, les permitió generar espacios de reflexión en torno a temáticas que, por la misma dominación, se mantienen invisibilizadas a partir de una naturalización. Otras, en cambio, mantuvieron los mismos modos de significar la realidad generándose una neutralización de las multiplicidades experimentadas, desde los patrones dominantes de significación de la heteronormatividad.

En relación a lo anterior, Bourdieu (2000) intenta dar una posible explicación a lo que él llama paradoja de la doxa -que la realidad del orden del mundo sea respetada, no transgredida- $y$ enfatiza esto mostrando su sorpresa respecto a la perpetuación de las relaciones de dominación en el orden establecido; perpetuaciones que no sólo están reforzadas por los que ejercen la dominación, sino también por los que la padecen. Su propuesta central se refiere a que entre las estructuras cognitivas -el modo de percibir y conocer el mundo-y las estructuras sociales $\mathrm{u}$ objetivas hay una concordancia, lo que lleva a ver las divisiones arbitrarias como naturales y por lo tanto, a que se perpetúen. O como plantea Derrida, la representación es imagen que se aparece ante 
cada sujeto para poder significar su mundo, pero es el propio mundo el que genera los límites de significación posible (1989).

De este modo, la menor existencia de referentes culturales para las prácticas eróticas entre mujeres -debido a la invisibilización que procura mantener una sociedad heteronormativainfluyó en el desconocimiento de los modos de aproximación erótica y de realización de las prácticas sexuales y afectivas que sostuvieron. Sin embargo, esta característica, que en varios casos implicó una mayor incertidumbre y obstaculizó los comienzos de dichos encuentros, también significó la posibilidad de una mayor creatividad al momento de sostener estos vínculos.

Aparece un nuevo erotismo en la mayoría de las entrevistadas, más abierto a la experiencia. El mandato de cumplir determinados roles asignados pierde su rigidez, lo que trae consigo una mayor amplitud en las formas de experimentar las diversas y nuevas representaciones de su corporalidad. Como plantea Jeffreys (1996), la sociedad heteronormativa sitúa a las mujeres como objetos disponibles sexualmente para los hombres, quedando invisibilizadas como sujetos. El placer para ellas queda indisolublemente ligado a la subordinación erotizada. Así, subordinación de las mujeres y dominación de los hombres conforman el lazo del deseo heterosexual. La experimentación de vivencias eróticas con una mujer, en tanto espacio de placer y reconocimiento, cuestiona en algunas de las mujeres entrevistadas el mandato del lazo heterosexual, permitiéndoles no quedar obligatoriamente posicionadas subjetivamente como objeto de deseo, sino que también como sujeto deseante, emergiendo el placer en el vínculo erótico. Por lo tanto, se genera una apertura al placer gracias a la experiencia erótica positiva con una mujer. Esto repercute en el modo de vivir el erotismo largo tiempo bloqueado en algunos casos, por temas como la dominación, el sometimiento y por el lugar obligado como objeto de deseo en el que quedaban por ser mujer. Apertura al placer que actúa como recuperación de un ámbito antes vedado o dañado. De este modo, la desrigidización de los roles que les permite este tipo de vínculo no normalizado, abre posibilidades de resignificación más creativas y por sobre todo, más expresivas de su propio deseo. 
Al transgredir las normas de género, no sólo las vivencias eróticas amplían sus límites, sino también aparecen modificaciones en la noción de sí. La mayoría de las mujeres del estudio no logran situarse en alguna de las posiciones determinadas por la heteronormatividad, ya sea valorada o devaluada. Esta nueva posición no logra ser aprehendida por los significantes designados en la matriz dominante ("heterosexual," "homosexual" por ejemplo) y tampoco a cabalidad, por otros significantes (por ejemplo, "bisexual") que -desde una hegemonía significante- intentan recapturar diversas prácticas que se escapan a su designación. Así, estas prácticas fuera de la norma, promueven un cuestionamiento del poder del nombre, de un nombre que, como sugiere Butler (2002), opera como sitio privilegiado de acción de los elementos de poder, como una marca del sistema de dominación, instalando la marca de la diferenciación sexual, del género y también del parentesco. De este modo, el nombrar, el denominar, no sólo opera como una manera de establecer una frontera, sino también como una forma de inculcar repetidamente una norma, la que termina por hacerse carne en ese cuerpo. "En nuestro mundo, divide y conquistarás debe convertirse en define y te apoderarás" (Lorde, 1979, 92).

Esta identidad móvil, en tránsito, puede ser concebida como una forma de resistencia a la hegemonía significante, pues se presenta como una identidad que no queda limitada por los mandatos de una realidad de dualidad obligada, complementaria y excluyente. Es en este sentido, que también estos nuevos modos de transitar una identidad pueden ser comprendidos como una identidad nómade, rizomática, en devenir. Identidad que se sostiene, no en una esencia cristalizada, sino que en una posición de resistencia a lo normativo, posibilitando en las mujeres del estudio, la apertura hacia multiplicidades identitarias, vinculares, eróticas y de la corporalidad. Así, lo nómade como propone Braidotti (2000), implica la disolución de la idea de centro inamovible, de una identidad auténtica, y más bien refiere la idea de una identidad como noción retrospectiva, como posible y necesaria de ser deconstruida y reconstruida continuamente; constantemente actualizada, funcionando como una forma de resistencia a las posturas dominantes de representación del yo. 
En otras palabras, "la conciencia nómade es una forma de resistencia política a las visiones hegemónicas y excluyentes de la subjetividad" (Braidotti, R. 2000: 58).

\section{Reflexiones finales}

Las mujeres del estudio, en su mayoría, manifiestan una identidad móvil, en tránsito, que no presenta la urgencia de una rígida delimitación designada por la matriz de sexo-género. Aparecen, entonces, diversas modalidades identitarias en ellas, las que presentan en común la transversalidad respecto de la visibilización y el cuestionamiento experimentado de una identidad obligada impuesta por los mandatos de género de la lógica imperante. Se genera así, un corte en la ilusión de continuidad de una identidad recibida por nacer en cuerpo de mujer.

Las prácticas que recorren lugares no normalizados, traen como consecuencia posible la desestabilización del lazo de verdad que amarra las dimensiones de la vida subjetiva: el deseo, la noción de sí y el cuerpo en el que se nace; ese nudo nunca se deshace totalmente, pero se suelta, se flexibiliza hacia nuevas significaciones. De este modo, el poder de verdad que ejerce la matriz de sexo-género pierde su intensidad respecto a dictaminar las bases únicas de una identidad, así como también de un erotismo y de un imaginario corporal viables. El sujeto de sexo/ género/deseo pierde su rígida coherencia.

Si bien las entrevistadas manifiestan diversos modos de experimentar el deseo hacia hombres y mujeres, así como distintas preferencias respecto a las prácticas sexuales, con hombres y con mujeres, en la mayoría de ellas aparece, generado por dichas vivencias eróticas no normalizadas, la apertura a un nuevo tipo de erotismo, así como a un nuevo modo de despliegue del mismo. Este nuevo erotismo aparece desmarcado de la genitalización que había sido la característica de las prácticas eróticas previas que habían mantenido exclusivamente con hombres. Algunas indicaron que al no estar determinada por la penetración fálica, este nuevo erotismo dejó de tener un punto central -heredado 
por la heteronormatividad- por lo que aparecieron diversas y más amplias modalidades eróticas.

Respecto a lo anterior, las vivencias de la corporalidad aparecen enlazadas a los nuevos modos del erotismo; se generó en ellas un despliegue de la corporalidad, una mayor sensibilización y la erogenización de nuevas zonas corporales. Esta nueva erogenización no obedeció a la lógica anterior, localizada, sino que se propagó de un modo más difuso y global por todo el cuerpo, desrigidizándose así, una corporalidad conformada bajo la exhaustiva vigilancia de la heteronormatividad. Estos cambios permitieron nuevos, más amplios modos y, en muchos casos, mayores grados de placer. Es posible pensar, entonces, que fuera de la dimensión normalizada, el mundo se diversifica, no sólo cambiando respecto a las formas, sino que además, respecto a determinados fundamentos que se encuentran a la base de aquellas formas.

Es posible, entonces, comprender los procesos que ellas narran, como una deconstrucción del sujeto de la sexualidad, de una sexualidad en donde deseo e identidad van indisolublemente unidos; como una deconstrucción de lo que Butler llama el sujeto de sexo/género/deseo (2001). La deconstrucción subvierte el orden jerárquico de centro y margen, permitiendo que lo marginal pueda ocupar también el lugar central. Este proceso de tránsito entre lo central y lo marginal, revela la estabilidad aparente de la jerarquía. Así, la deconstrucción de una sexualidad, genera una desestabilización de la jerarquía heteronormativa -donde género, sexo y deseo son entendidos como uno- apareciendo el deslizamiento continuo entre las partes. Se produce una apertura a un nuevo erotismo, desplegado por distintas vías, donde ya no prima lo genital dictado por la matriz de sexo-género; un erotismo menos rígido, más móvil y más difuminado. De este modo, un erotismo rizomático, desplaza la dualidad -que obliga una mutua exclusión de las partes para poder sobrevivir- permitiendo la entrada a múltiples posibilidades, que se suman unas a otras, abriendo puertas a un erotismo no disciplinario. 


\section{Notas}

1 Este artículo se realiza sobre la base de la investigación para la Tesis del Magíster en Estudios de Género y Cultura, Mn. Ciencias Sociales: Imaginario Corporal y Prácticas Sexuales. Representaciones del cuerpo en mujeres desde prácticas sexuales con hombres y con mujeres. Universidad de Chile, 2008.

2 Psicóloga, Universidad Católica de Chile. Magíster en Estudios de Género y Cultura, mención Ciencias Sociales, Universidad de Chile.

\section{Bibliografía}

Bourdieu, Pierre. La dominación masculina. Barcelona: Anagrama, 2000.

Braidotti, Rosi. Sujetos nómades. Argentina: Paidós, 2000.

Butler, Judith. El género en disputa. México: Paidós, 2001.

----- Cuerpos que importan. Argentina: Paidós, 2002.

Deleuze, Gilles y Guattari, Félix. Rizoma. Introducción. España: PRETEXTOS, 2003.

Derrida, Jacques. La desconstrucción en las fronteras de la filosofía. Barcelona: Paidós, 1989.

Foucault, Michel. Historia de la Sexualidad. 1- La Voluntad de Saber. Argentina: Siglo XXI Editores, 2002.

Jeffreys, Sheila. La herejía lesbiana. Una perspectiva feminista de la revolución sexual lesbiana. Madrid: Ediciones Cátedra, 1996.

Kristeva, Julia. Poderes de la perversión. Argentina: Catálogos Editora, 1988.

Lorde, Audre. Las herramientas del amo nunca desarmarán la casa del amo. 1979. En Moraga, Cherríe y Ana Castillo. Esta Puente, mi Espalda. San Francisco: Editorial Ismo, 1988. 